\title{
BETTER WORLD THROUGH BETTER DECISION MAKING
}

\author{
Thomas L. Saaty \\ University of Pittsburgh \\ Email: saaty@katz.pitt.edu
}

\begin{abstract}
To change this world from its primitive habit of using words and language to arrive at decisions by making tradeoffs which require the use of numbers, we need to work hard to promote this way of thinking to teach the whole world and its politicians how to measure the intangibles involved in the decisions they make and how to work together peacefully.
\end{abstract}

Key words: Decision Making, The AHP; Sensitivity analysis; negotiations; Conflict resolution

\section{Introduction}

Our world today is more and more moving from fragmentation to integration becoming better unified and interactive in its economics, information sharing, travel, diplomacy, and in medical instruments and the importance of health and even in waging wars. There is more freedom for individuals to express themselves. It is by having a one world view that we will be able to make the best decisions. As more people express themselves, they need a way to make decisions together. Conflicts can be resolved rationally and peacefully if concessions can be traded off and by using the Analytic Hierarchy Process (AHP) which allows for the measurement of intangibles alongside tangibles better decisions can be made about the tradeoffs. Accuracy of outcome is assured by making judgments directly and by then performing sensitivity analysis. Seeing the big picture and being able to combine pieces of thinking, including positive and negative aspects of the problem, are made possible by combining analysis and synthesis scientifically in a manner that makes sense to our brain. In group decision making, building the model allows different expertise and level of authorities to be represented.

Overall change and the acceleration of change influences human psychology. We as individuals and as groups seem unable to cope with the unpredictable change and growing complexity in the world. Stress, uncertainty and frustration increase, minds are overloaded with information and knowledge fragments and values erode. Negative developments are consistently overemphasized, while positive ones are ignored. The resulting climate is one of nihilism, anxiety and despair. While the wisdom gathered in the past has lost much of its validity, we don't have a clear vision of the future either. As a result, there does not seem to be anything left to guide our actions.

According to the Swiss born French philosopher Jean-Jacques Rousseau (1712 -1778), original ("Natural") man had no language, no abstract thought, no moral ideas and no society. He was selfcentered but not cruel and felt compassion for his kind. He was good but not capable of moral values and of self-sacrifice. As a "perfectible" species, not fixed genetically like the animals, he was able to create culture and society and a history. The steps in his development hinged on advances in metallurgy, agriculture and property. Social living brought about radical psychological changes. Rousseau's view is 
that self-love turned into aggressive competitive hostility and a state of war among men. Exploitation of others is used for self-aggrandizement. In society, man is "naturally" more evil than virtuous and his selfinterest is in constant opposition to the general interest. Social life is characterized by the alienation of men from nature, from each other and from authentic selves. The conflicting demands of instinctual nature are constantly at war with the impositions of society. The cure requires the fabrication of a new man and the proper political institutions. It is not enough for men to obey the laws. Their minds and wills must also be engaged. The people are sovereign and through universal suffrage may be able to participate in the expression of the general will in law under the direction of "guides" or moderators who know the general will in advance.

Someone wrote about "Changing the World" as follows: Yesterday I was clever so I wanted to change the world. Today I am wise, so I want to change myself.

"To make the world a better place" it must be peaceful, more spiritual, more intellectual, more meaningful. We need a framework that ties everything together, that allows us to understand society, the world, and our place in it, and that could help us to make the critical decisions which will shape our future. It would synthesize the wisdom gathered in the different scientific disciplines, philosophies and religions. It would enable combining attention to function and design, logic and empathy. In essence, we need to make decisions a framework that allows us to use the power of both our left and right brains harmoniously.

These are the questions we need to ask: "Who are we? Why is the world the way it is? Where are we going? What is good and what is evil? How should we act? What is true and what is false?"

World views cannot be developed from scratch. We need building blocks to start with. These building blocks can be found in existing theories, models, concepts, guidelines and values, scattered over the different disciplines and ideologies. Fragments of world views need to be our starting point. By including these concerns as the building blocks in an AHP/ANP framework, we can both break them down into their components, and relate them so we can prioritize the actions we need to take to control and direct these multiple competing interests.

Real life problems exhibit:

1) Strong Pressures and Weakened Resources;

2) Complex Issues - Sometimes there are No "Right" Answers;

3) Vested Interests;

4) Conflicting Values.

Most decision problems are multi-criteria with conflicting demands:

1) Maximize profits;

2) Satisfy customer demands;

3) Maximize employee satisfaction;

4) Satisfy shareholders;

5) Minimize costs of production;

6) Satisfy government regulations; 


\section{T. L. Saaty/Better world through better decision making}

7) Minimize taxes;

8) Maximize bonuses

People or individuals decide on:

1) Important things to buy;

2) Schools for children;

3) Places to live;

4) Spouse to marry;

5) Doctor for health;

6) Medical Operation - to have or not to have;

7) Places to vacation and on and on.

\section{Importance of Decision Making}

Our world is moving from one in which economy and society is built on a logical and linear way of thinking to one which is more interactive and that requires systemic thinking. Strong pressures constrained by weakened resources require an approach that simultaneously considers the different aspects of the situation. Leaders face complex issues which sometimes have no "right" answers, actors with different interests, and even conflicting values.

Decision making has to be the most important thing we do, including believing in religion. We decide to believe in God, but our beliefs do not come to us by magic. Often things are decided for us by society, by our parents, teachers and people we love and admire. But how did they come by their own beliefs? Are they more rational and thoughtful than we are?

The great French mathematician and philosopher Rene Descartes, who invented the subject of analytic geometry on which the calculus depends strongly, wrote "I think, therefore I am." It is might have been more accurate for him to say, "I decide, therefore I am."

We need to learn about how to make complex decisions from the roots up and from the top down. How? There are two parts to any decision: its factors and their connections, and the judgments we use to prioritize their importance.

Decisions are concerned with measuring importance, preference, and likelihood of influences. We make pairwise comparisons to judge how much one element dominates another with respect to a certain property; that is, how much more important or more preferred or more likely it is.

We learn as we make decisions, and often groups of people must make a decision. We need to work together to make the right decisions, and the definition of a right decision might be one that the group can get together and implement. Decisions need to consider the group members and their opinions and include their judgments and take account of who has what knowledge and power. We can also ask, looking in the rearview mirror long after, if a decision was the right one in view of what happened as a result of it. Was what resulted from it good in the short term and in the long term? 
Our decisions must cover all the goods and bads exemplified in the benefits and the costs of the choices (in the present) and in their opportunities and risks (in the future). Decisions need structures that include all the goals, factors and alternatives we have in mind along with our overall strategic objectives as individuals or as a group. Most importantly, decisions need informed judgments. We need to be able to measure intangibles to make tradeoffs among the many criteria we may have to consider. Despite the complexity of the problem at hand, the level of sophistication of our view of it, our model, should be at the decision maker's discretion so as not to be too overwhelming to be effective. It is more important to have a less complex model that triggers actions rather than a more sophisticated one that would paralyzes with too much detail.

\section{Decision Making Involves the Following Kinds of Concerns}

Multi-criteria decision making involves many criteria and we need to make tradeoffs among them. To make accurate tradeoffs we need numbers; what numbers and how? Are the numbers valid and how do we know?

Decision making involves all of these things: measuring intangibles; planning; generating a set of alternatives; setting priorities; choosing a best policy after finding a set of alternatives; allocating resources; determining requirements; designing systems; predicting outcomes; measuring performance; insuring the stability of a system; optimizing; resolving conflict; and performing benefits, opportunities, costs and risks (BOCR) analysis. The need to structure a problem by identifying relevant elements. Making those elements explicit allows one to design innovative actions by exploring certain combination of elements. We could generate alternatives through creative design.

\section{On Measuring Intangible Factors}

By definition an intangible is something for which there is no scale of measurement. When we measure something using an existing scale, we get numbers which we then interpret for how adequate they are for the purpose we have in mind. Measurements have no intrinsic meaning. A measurement is useful only when we understand what it means in the context we plan to use it. Our minds must always tell us what numbers mean and our minds think in subjective ways to satisfy our needs. The value of a measurement changes depending on how we will use it.

Thus objectively derived numbers through measurement must always be subjectively interpreted. There is no other way than subjectively interpreting measurements in terms of our experience to turn numerical measurements that then become objective when we all agree on the purpose for which the measurements will be used.

This is the scientific approach, first we measure, then we use judgment to interpret the results. Contrast that with decision making, in which we first make judgments that are used to create measurement scales that serve as priorities. It is the opposite approach.

In decision making with the AHP we use a fundamental scale of absolute numbers to compare things on each property, derive a priority scales for the elements measured with respect to that property and then synthesize all these priorities to obtain a single overall scale, a uni-dimensional scale. That result replaces what one does in science to interpret things at the end from formulas. The difference is that we have 


\section{T. L. Saaty/Better world through better decision making}

specific measurements tailored to the situation, whereas formulas give a composite result involving many scales like miles per hour or foot-pounds that it takes expertise to interpret.

There is no complex decision for which we know the best alternatives and the best answer unless we collectively do an analysis of their benefits, opportunities, costs and risks (BOCR) and agree on the strategic goals and their priorities the decision is presumed to serve that then help us to combine the BOCR into an overall final answer.

I believe that we really don't know what the best outcome of a decision is until we do that. If asked in advance we must say we don't know. Even if experience gives us some sense of ideas with regard of the best outcome, we need to do that and see whether the result of the BOCR analysis support the intuition. If it is not, we need to study the model to learn on what causes the difference. We should assume neither the result of our BOCR analysis nor our intuition is correct, although at the end they need to come to the same result. In this situation, a learning process needs to take place where we either find our bias or inaccurate judgments in the model that needs to be revised. In extreme case, we may even find that an important element is missing from the model. Being able to measure intangibles is what makes it not only possible but also necessary to do this kind of analysis.

\section{People still don't believe Feelings are Quantifiable; We have shown they are}

Davis and Hersh say in their book (1986) Descartes Dream, Harcourt Brace and Jovanovich, New York, "If you are more of a human being, you will be aware there are such things as emotions, beliefs, attitudes, dreams, intentions, jealousy, envy, yearning, regret, longing, anger, compassion and many others. These things — the inner world of human life — can never be mathematized."

In their book Einstein's space and Van Gogh's sky: Physical reality and beyond, Macmillan, 1982, Lawrence LeShan and Henry Margenau write this:

We cannot as we have indicated before, quantify the observables in the domain of consciousness. There are no rules of correspondence possible that would enable us to quantify our feelings. We can make statements of the relative intensity of feelings, but we cannot go beyond this. I can say, "I feel angrier at him today than I did yesterday. We cannot, however, make meaningful statements such as, I feel three and one half times angrier than I did yesterday The physicists' schema, so faithfully emulated by generations of psychologists, epistemologists and aestheticians, is probably blocking their progress, defeating possible insights by its prejudicial force. The schema is not false-it is perfectly reasonablebut it is bootless for the study of mental phenomena."

In the ordinal way that people believe in, one can say that A is preferred to B but not by how much. Language and logic are based on such comparisons made without being able to include how much A is 
preferred to B. A.F. MacKay writes that pursuing the cardinal approaches is like chasing what cannot be caught. He is wrong!!!

It is known to cognitive psychologists that making comparisons is an intrinsic biological talent that we have. In addition, this talent is used by all people no matter how educated or talented they are. Comparisons can be applied by an expert to derive relative numbers to represent their idea of relative importance or priority. To make sense of these priorities one must have corresponding feelings whose intensity more or less corresponds to the value of the numbers.

In his book The Number Sense, How the Mind Creates Mathematics, the mathematician and cognitive neuropsychologist Stanislas Dehaene (Oxford University Press 1997, p.73) writes "Introspection suggests that we can mentally represent the meaning of numbers 1 through 9 with actual acuity. Indeed, these symbols seem equivalent to us. They all seem equally easy to work with, and we feel that we can add or compare any two digits in a small and fixed amount of time like a computer. In summary, the invention of numerical symbols should have freed us from the fuzziness of the quantitative representation of numbers."

Prioritization is determined by measuring the strength of people's feelings. We derive priorities about the intensity of how we feel about the importance, preference, or likelihood of the factors when making pairwise comparisons. First we make the judgments, next we derive the priorities. Priorities do not somehow exist in nature for us to learn about; they arise from human purpose.

What is the special value of decision making to the world? Does decision making drive economic growth? What is decision making like? What is its history, nature, environment, and what are some of the underlying diversities or challenges it is facing? Assuming decision making is important to economic growth, how can public policy help to enhance decision making? Finally, based on the empirical findings and potential policy implications, future directions of investigation are suggested.

\section{Most General Law of Nature}

The most general law of nature that also applies to humans is the Law of Influence. Every other law including the laws of physics and the laws of crime and punishment are special cases of that law. Influence is the power or capacity to produce an effect, a consequence. An effect is a relative change in state. The law says that everything has an influence great or small on something including itself. Influences are eternal. The opposite of influence is nothingness.

While the critical role of influence in almost all analyses is paramount, there is always the question of how to identify it in a way that humans can comprehend it. In essence, it is how to measure it. The challenge is to determine what influences there are and what their effects would be and how best to act on them when our short and long term interests are concerned. Scenarios can be used for that purpose.

Always look for influences (control criteria), determine their kind: economic, social, political, technological, psychological etc. and learn to prioritize their importance and dominance. Prioritize their 


\section{T. L. Saaty/Better world through better decision making}

potential effects on the people involved and their preferences and learn to synthesize them to find the best actions you can take to satisfy your goals (strategic criteria) in the face of these influences.

\section{Decision Making Challenges}

A 20 year study of over 400 business decisions made by public, private and not-for-profit organizations in the United States, Canada \& Europe (Nut, 2002) showed that the current state of corporate decision making is deplorable, with time wasted in inefficient meetings that often resulted in decisions that had disastrous consequences.

\section{Current State of Corporate Decision Making-Better World?}

- At least $50 \%$ of all decisions end in failure.

- $33 \%$ of all decisions made are never implemented.

- $50 \%$ of decisions implemented are discontinued after 2 years.

- $66 \%$ of decisions are based on failure prone methods.

- Decisions using high participation succeed $80 \%$ of the time, but occur only $20 \%$ of the time.

- Practically every decision failure is preventable.

- Only $37 \%$ of decision makers said they have a clear understanding of what their organization is trying to achieve.

- Only 1 in 5 was enthusiastic about their team's and organization's goals.

- Only 1 in 5 said they have a clear line of site between their tasks and their organization's goals (from a Harris Poll of 23,000 respondents).

\section{Inefficient Meetings}

Those of us who participate regularly in meetings know that there is a lot of wasted time. Sometimes we wonder if what is accomplished in those meetings is worth the investment of time (Nelson, et al., 1995). Here are some statistics about meetings that seem to suggest our skepticism might be right (Nelson, et al., 1998).

- 11 Million meetings in the U.S. per day

- Most professionals attend a total of 61.8 meetings per month

- Research indicates that over 50 percent of this meeting time is wasted

- Professionals lose 31 hours per month in unproductive meetings, or approximately four work days

\section{Benefits of Systematic Decision Making}

Along with the negatives above we recognize that meetings are important. Without them we would be in a dictatorship. By using a systematic framework for decision making, for instance, a structured decision making process such as the AHP, we can turn wasted meetings into productive meetings. Some of the benefits are listed below.

- Rapidly build consensus on goals, objectives and priorities

- Align work activities to what is important for organizational success 
- Use objective-based budgeting versus resource-based budgeting

- Get past corporate stovepipes (tear down the walls around corporate departments)

- Improve speed and effectiveness of decision making

- Synthesize existing corporate data with management priorities

- Achieve buy-in on major corporate decisions

- Improve accountability and outcomes over time

- Achieve cost savings through efficient allocation of resources

\section{Knowing Less, Understanding More}

You don't need to know everything to get to the answer. Expert after expert missed the revolutionary significance of what Darwin had collected. Darwin, who knew less, somehow understood more. Darwin seemed to be able to put isolated things he knew into a certain context, perceiving those as a whole and making him understand more. The experts knew many things, but Darwin knew one big thing by synthesizing whatever limited things he knew. Analysis and synthesis are both essential to human reasoning. Understanding alone would not have led Darwin to such a revolutionary idea. He must have been practicing creative thinking, either consciously or unconsciously.

Philosophers of science are in wide agreement that empirical science depends for its operation upon subjective and inter-subjective structures that allow objective knowledge to emerge and stabilize. Sensory exteriors depend on non-sensory interiors that are just as real and just as important. (Wilber, 1998)

In next year, next century, people will need to solve many problems to build up a better world. It could mean we will have no more poverty, or better education, or simply we will have more time with family. We need to practice at making decisions together and make it both a serious activity and a hobby. Just as the use of computers has become wide spread even among children, so would knowledge and practice about making decisions can also become widespread.

If you look at the decisions you've made about features, benefits, pricing, timing, hiring, etc., how many of them are obviously 'better' from your point of view, and how many people might disagree? There are very few markets where majority rule is the best way to grow. We know many personal, professional, and global issues can be lessened, and even solved, simply through helping millions of people to consider and focus on what is important to them, the life they would like to have, and the kind of world in which they want to live. Our deep reaching, high-impact approach involves bringing people together, building capacities, expanding our impact exponentially, reaching those in need that few programs ever touch, and helping change countless lives.

Research has shown that a greater focus on meaning, direction, and impact, especially when one decides it on their own, is a foundation of well-being, resilience, morale, healthier relationships, performance, and many other benefits to the individual. It also establishes that through connectivity, every step, no matter how small, affects our families, workplace, community, and even people you will never meet.

In fact, as we meet with leaders across the private, public, and nonprofit sectors, each person shares with us the connection they see between how we do group decision making and their work in education; health; poverty reduction; hunger relief; community development; democracy and governance; human 


\section{T. L. Saaty/Better world through better decision making}

rights; economic development; crime prevention; performance management; furthering peace; and many other fields. And, they are all correct.

We must involve people in decision making as thoroughly as we can. Well, then would the answer not be to increase the number of people who understand the wealth inside them? To tell them how their faith, their ideas, their talents, their genius can spark an enormous change? Change is just that-we are only moments away from it. A spark. A moment. An inspiration. A premonition. The change maker is ultimately, in most idealized form, the doer, the innovator, the entrepreneur. We are the mad visionaries, thinkers, writers, poets, doers, lovers, outlaws, rebellious, misfits. We are probably from the underprivileged, under-resourced, underserved communities, poor and without. But that fire is within us. We need to be supported and to support each other and if we can learn to work together in groups to make effective decisions that improve life for all of us, that is a way to do it.

\section{Decision Making must inevitably become a Unifier and Pacifier of a Fragmented World}

Because everything we do needs deciding, we need to learn to structure our world as a giant network of networks within which the priorities we determine for them can work to guide our actions. Our minds should become less random in accounting for the future when we are all familiar with the complex world we live in and how it works. Recalling what Rousseau said, we not only need to recognize human shortcomings, but consciously work to change them for the better. That could help make a better world.

\section{Bibliography}

Nelson, Robert B. and Economy, Peter. 1995. Better Business Meetings . Burr Ridge, IL : Irwin, Inc., 1995.

-. 1998. Meetings in America: A study of trends, costs and attitudes toward business travel, teleconferencing, and their impact on productivity. Greenwich, CT : INFOCOMM, 1998.

Nut, Paul. 2002. Why Decisions Fail. San Francisco, CA : Berret \& Koehler, 2002.

-. 2002. Why Decisions Fail. s.l. : Berret \& Koehler, 2002.

Pink, Daniel H. 2006. A Whole New Minds: Why right-brainers will rule the future. New York: Riverhead Books, 2006.

Wilber, Ken. 1998. The Marriage of Sense and Soul. New York : Broadway Books, 1998. 